\title{
Strength of the shaft/hub joint using a finite element model
}

\section{Resistencia de la unión eje/cubo mediante un modelo por elementos finitos}

SALGADO-CRUZ, Manuel†**, CORTÉS-GARCÍA，Claudia，SZWEDOWICZ-WASIK，Dariusz Slawomir and MARTÍNEZ-RAYÓN, Eladio

\section{Tecnológico Nacional de México / Centro Nacional de Investigación y Desarrollo Tecnológico (CENIDET)}

ID $1^{\text {st }}$ Author: Manuel, Salgado-Cruz / ORC ID: 0000-0001-7304-4088, CVU CONACYT ID: 514375

ID $1^{\text {st }}$ Coauthor: Claudia, Cortés-García / ORC ID: 0000-0002-0474-2533, CVU CONACYT ID: 62954

ID $2^{\text {nd }}$ Coauthor: Dariusz Slawomir, Szwedowicz-Wasik / ORC ID: 0000-0002-4788-0856, CVU CONACYT ID: 12438

ID $3^{\text {st }}$ Coauthor: Eladio, Martínez-Rayón / ORC ID: 0000-0003-3846-6888, CVU CONACYT ID: 83893

DOI: $10.35429 /$ JSTA.2019.15.5.9.18

Received March 15, 2019; Accepted Jun 20, 2019

\begin{abstract}
This article describes the effect of the roughness size on the axial slip strength between the parts of shaft/hub joints with interference fit. The surface roughness was obtained from a turning process with different finishes (fine, medium and rough). A finite element modeling was developed, which uses a normal contact stiffness $k_{n}$ equivalent to the size of the surface roughness between the joint pieces to represent the real contact. In order to validate the numerical model, theoretical results of contact pressure and extraction force of the shaft/hub joint with smooth elements were compared with the corresponding numerical results obtained. The numerical results from studies that considered the size of the surface roughness showed that the axial load capacity of the joint decreased with larger roughness.
\end{abstract}

Normal contact stiffness, Surface roughness, Extraction force

\begin{abstract}
Resumen
Este artículo describe el efecto del tamaño de las rugosidades en la resistencia al deslizamiento axial entre piezas de uniones eje/cubo con interferencia. La rugosidad superficial se obtuvo de un proceso de torneado con diferentes acabados (fino, medio y rugoso). Se desarrolló un modelado por elementos finitos que utiliza una rigidez normal de contacto $k_{n}$ equivalente al tamaño de la rugosidad superficial entre las piezas de la unión para representar al contacto real. Para validar el modelo numérico, se compararon resultados teóricos de presión de contacto y fuerza de extracción de la unión eje/cubo con elementos lisos con los correspondientes resultados numéricos obtenidos. Los resultados numéricos de estudios que consideraron el tamaño de la rugosidad superficial mostraron que la capacidad de carga axial de la unión disminuyó con rugosidades de mayor tamaño.
\end{abstract}

Rigidez normal de contacto, Rugosidad superficial, Fuerza de extracción

Citation: SALGADO-CRUZ, Manuel, CORTÉS-GARCÍA, Claudia, SZWEDOWICZ-WASIK, Dariusz Slawomir and MARTÍNEZ-RAYÓN, Eladio. Strength of the shaft/hub joint using a finite element model. Journal of Scientific and Technical Applications. 2019, 5-15: 9-18.

\footnotetext{
* Correspondence to Author (email: manuelsc@ cenidet.edu.mx)

$\uparrow$ Researcher contributing first author.
} 


\section{Introduction}

Shaft / hub joints are based on the principle of interference settings: they depend on the difference in diameters to be able to join. The assembly is done by pressure or temperature. The absence of conventional fastening such as the use of keys, thread or wedges, makes them compact and aesthetic in appearance (Ramachandran \& Radhakrishnan, 1974). Due to the low manufacturing cost, easy assembly and compact integrity, interference settings provide high torque and axial forces (Buczkowski \& Kleiber, 2016).

Its applications are: in cutting tool holders, wheels and bands for railway material, turbine discs, rotors for electric motors, pulleys and for locating ball and roller bearings. They are also an effective way to assemble machine elements, such as a gear to a shaft to transmit torque and resist axial thrust through friction resistance. (Booker \& Truman, 2011).

Ramachandran \& Radhakrishnan (1974) defined the factors that affect the performance of an interference fit, which are: (1) shaft diameter; (2) outer diameter of the hub; (3) joint length; (4) amount of interference; (5) properties of the shaft and hub material; (6) surface finish of contact surfaces.

The effect of the first five factors on the carrying capacity of an interference fit can be determined mathematically using the theory of elasticity for pressurized cylinders (Budynas \& Nisbett, 2008). But, the effect of the surface finish of the contact surfaces is complex to analyze by theoretical calculations, since the irregular nature of the contact surfaces must be considered (Ramachandran \& Radhakrishnan, 1974). Within the surface finish, the parameter with the greatest influence is surface roughness.

Below are the studies or techniques that consider the roughness in the strength of the shaft / hub joints, we have:

Yang et al (2001) They showed that the roughnesses play an important and positive role in the cylindrical interference fit. They recommend using economical manufacturing processes such as turning to produce adjustment surfaces, rather than methods such as polishing that are much more expensive.
Yang et al (2002) they propose a simple model to calculate the actual pressure of an adjustment with interference. This model consists in replacing the complex real area with an equivalent area.

Boutoutaou et al (2011) analyzed the extraction force for the hub-shaft joint numerically varying shape defects (lobes). They concluded that the extraction force increases as the number of lobes increases.

Boutoutaou et al (2013) they presented a technique of numerical homogenization in the behavior of a temperature interference adjustment. This approach allows considering the influence of roughness in the modeling of industrial parts that usually have a complex geometry. The modeling results show that the prediction of the resistance to extraction in the use of the homogenized elements was improved compared to an approach that considers the surfaces in contact between the two perfectly smooth assembled parts (without roughness).

Buczkowski \& Kleiber (2016) provided a methodology to improve the design of a temperature assembly. They considered the roughness of the pieces and introduced a nonclassical friction hardening law, in which the tangential micro-glides are considered. They concluded that smooth surfaces achieve greater load capacity.

As can be seen in this review of the works, we find two aspects. One mentions that the roughness generates a greater axial resistance, but it should be noted that they take as reference the midline of the roughness profile as the nominal diameter of the piece. The other side concludes that the smooth surfaces contribute to a greater resistance of the joint, the roughness profile is considered not to exceed the nominal diameter. This way of analyzing the roughness is considered more attached to the reality of measuring the diameters of the pieces that will form the shaft / hub joint. Figure 1 shows an example of how the surface roughness profile is considered with respect to the nominal diameter of the piece, where it is considered that the roughness profile peaks do not exceed the nominal diameter. 
Nominal measure

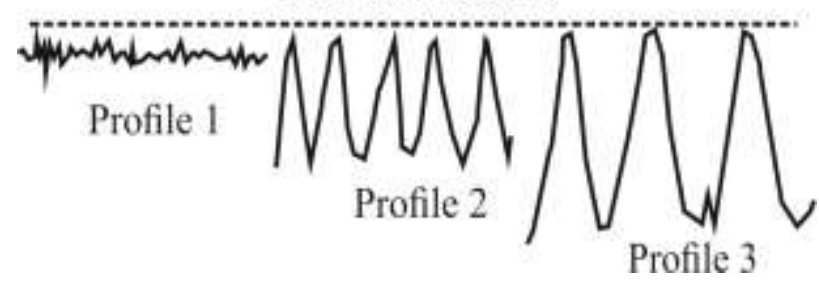

Figure 1 Consideration of the nominal diameter with respect to the roughness profile

Due to these uncertainties, a hypothesis is proposed to know the effect of surface roughness on the load capacity of the shaft / hub joint.

In the present study, a finite element model will be developed with the objective of analyzing and evaluating the axial resistance of an axis-hub joint with interference adjustment Ø20H7 / s6, based on the study on normal contact stiffness, which will be in function of the surface roughness of the surface. This normal contact stiffness will represent the complex geometry of the roughness profile for light and practical modeling.

\section{Theoretical framework}

This section presents the equations required to measure contact pressure, extraction force and radial and tangential stresses. In addition, the equation that considers surface roughness is presented by means of normal contact stiffness.

\section{Contact pressure}

Acording to Budynas \& Nisbett (2008) when two cylindrical parts are assembled by contraction or by pressure on each other, a contact pressure $p$ is created between the two parts.

$$
p=\frac{\delta}{\frac{d}{E_{o}}\left(\frac{d_{0}{ }^{2}+d^{2}}{d_{o}{ }^{2}-d^{2}}+v_{o}\right)+\frac{d}{E_{i}}\left(\frac{d^{2}+d_{i}{ }^{2}}{d^{2}-d_{i}{ }^{2}}-v_{i}\right)}
$$

Where $d$ is the nominal diameter of the axis, $d_{i}$ is the internal diameter (if any) of the axis, $d_{o}$ is the external diameter of the cube, $E$ is Young's modulus and $v$ is Poisson's ratio, with subscripts $O$ and $i$ for the hub and shaft, respectively (Figure 2).

When the shaft and hub are of the same material, it would be.

$$
p=\frac{E \delta}{2 d^{3}}\left[\frac{\left(d_{o}^{2}-d^{2}\right)\left(d^{2}-d_{i}^{2}\right)}{d_{o}^{2}-d_{i}^{2}}\right]
$$

On the other hand, $\delta$ is the diametral interference between the axis and the cube, that is, the difference between the external diameter of the axis and the internal diameter of the cube.

$$
\delta=d_{\text {axis }}-D_{\text {cube }}
$$

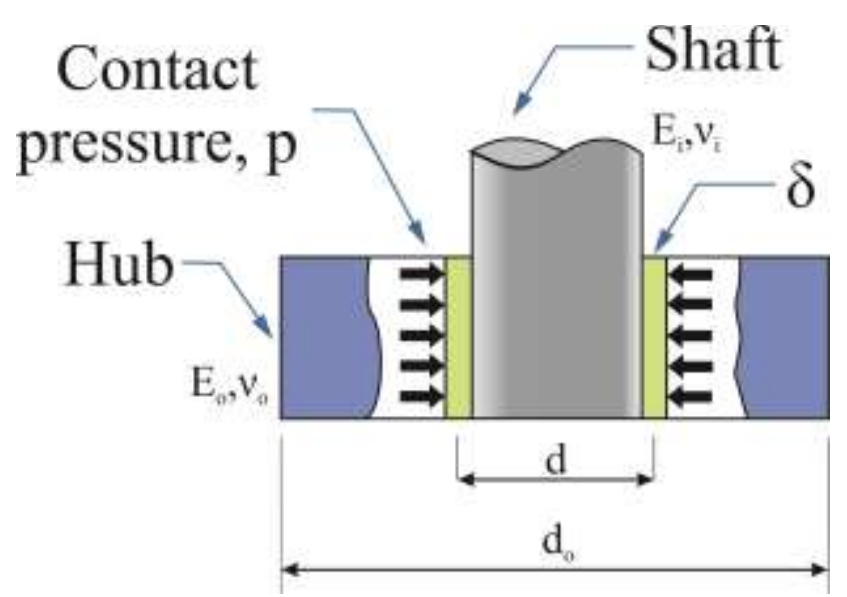

Figure 2 Parameters involved in the contact pressure of the shaft / hub joint

As there will be tolerances in both diameters, the minimum and maximum pressure can be found by applying the minimum and maximum interference (see Figure 3), which are expressed in equation (4) and (5) respectively.

$$
\begin{aligned}
& \delta_{\text {min }}=d_{\text {min }}-D_{\text {max }} \\
& \delta_{\text {max }}=d_{\text {max }}-D_{\text {min }}
\end{aligned}
$$

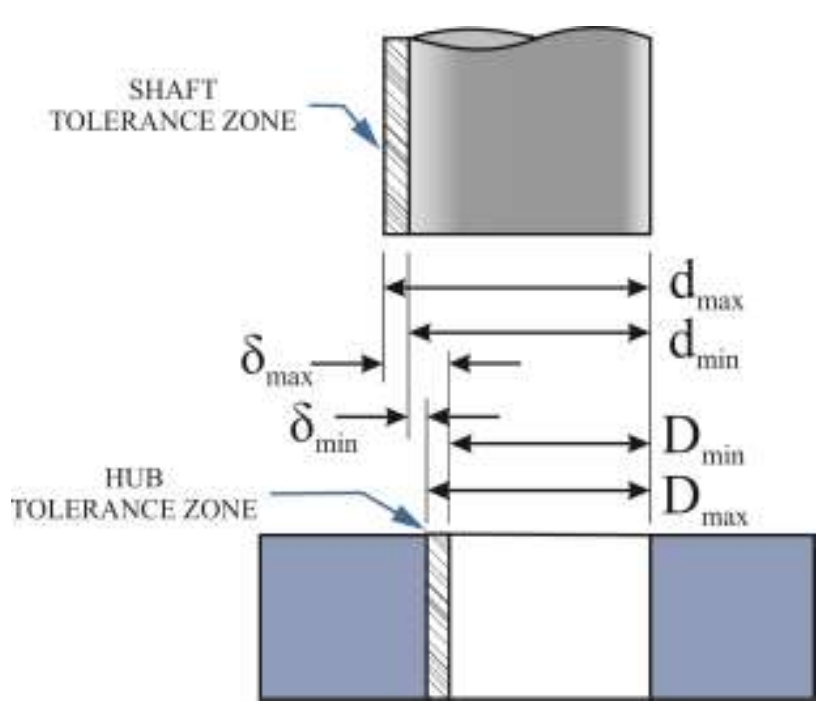

Figure 3 Minimum and maximum interference due to shaft and hub tolerances 


\section{Radial and Tangential Efforts}

The stresses due to an interference fit can be obtained by considering the shaft as a cylinder with uniform external pressure, and the hub as a hollow cylinder with a uniform internal pressure.

The tangential stresses in the shaft and hub contact are:

$$
\begin{aligned}
& \sigma_{t, \text { shaft }}=-p \frac{d^{2}+d_{i}{ }^{2}}{d^{2}-d_{i}{ }^{2}} \\
& \sigma_{t, \text { hub }}=-p \frac{d_{0}{ }^{2}+d^{2}}{d_{o}{ }^{2}-d^{2}}
\end{aligned}
$$

Radial efforts in contact are simply:

$\sigma_{r, \text { shaft }}=-p$

$\sigma_{r, h u b}=-p$

\section{Extraction force}

The extraction force or axial resistance is the product of the static friction coefficient $\mu_{s}$ and the normal load $W$ acting on the contact interface between the shaft and the hub. The normal load can be represented by the product of the pressure $p$ and the nominal contact area $A_{0}$. Therefore, the extraction force $F_{\text {extraction }}$ is:

$$
F_{\text {extraction }}=\mu_{s} W=\mu_{s}\left(p A_{0}\right)=\mu_{s} p \pi d L_{c}
$$

Where $L_{c}$ is the length of the cube.

\section{Consideration of roughness by means of normal contact stiffness}

To consider the effect of surface roughness on normal contact, Buczkowski \& Kleiber (2016) recommend that for engineering applications, the normal contact stiffness of rough surfaces $k_{n}$ for a nominal pressure $W / A_{0}$ can be estimated by the following equation:

$$
k_{n=\frac{3}{2}} \frac{W}{A_{0} \sigma}
$$

Where $W$ is the normal contact load, $A_{0}$ It is the nominal area of contact and $\sigma$ denotes the standard deviation of the rough surface.
The $\sigma$ is the most common measure of dispersion, which indicates how scattered the data is with respect to the mean. The greater the standard deviation, the greater the dispersion of the data. Figure 4 shows how the actual contact of the surface roughness can be represented by a normal contact stiffness.

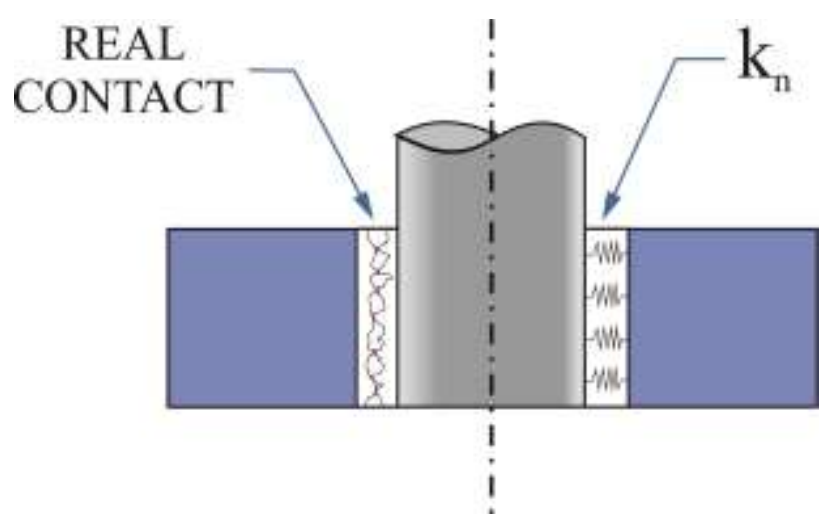

Figure 4 Consideration of roughness by means of normal contact stiffness

\section{Experimental data for the model}

\section{Standard deviation of a turning process}

Following is the obtaining of the standard deviation $(\sigma)$ of a turning process. The axes were machined on a conventional lathe. The surface finish was smooth, medium and rough. 5 axes were machined for each surface finish. Subsequently, the standard deviation of the surface roughness of the different finishes was measured, with the help of a roughness meter. Finally, an average standard deviation value was obtained for each surface finish.

\section{Shaft Machining}

15 axes were machined on a conventional lathe (Figure 5). The surface finish was fine, medium and rough (Figure 6). The material of the shafts was steel AISI 1045.

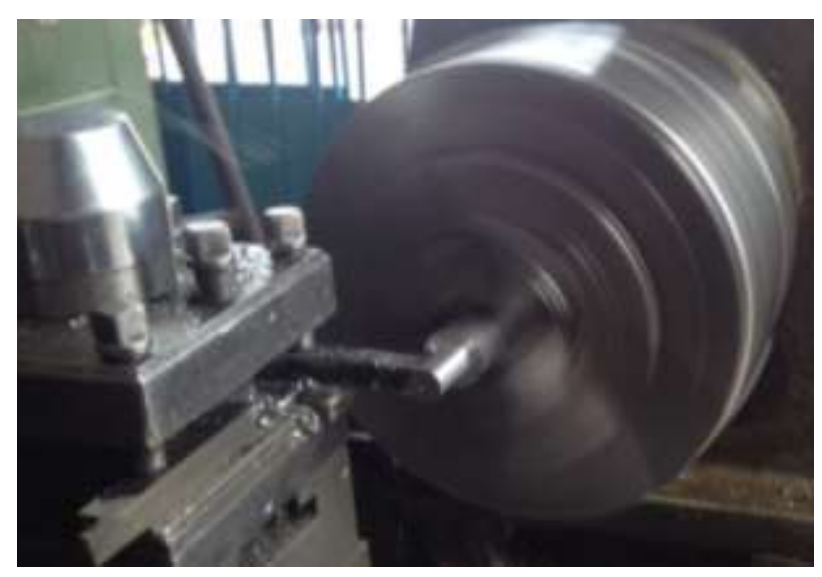

Figure 5 Conventional Lattice Machining

SALGADO-CRUZ, Manuel, CORTÉS-GARCÍA, Claudia, SZWEDOWICZ-WASIK, Dariusz Slawomir and MARTÍNEZRAYÓN, Eladio. Strength of the shaft/hub joint using a finite element model. Journal of Scientific and Technical Applications. 2019. 


\section{Measurement of the standard deviation of surface roughness}

The $\sigma$ measurements of the different surface finishes were made. The instrument used was a sj-210 rugosimeter of the Mitutoyo brand. Table 1 shows the characteristics of roughness measurements.

\begin{tabular}{|l|l|}
\hline Norm & ISO 1997 \\
\hline Profile & $\mathrm{R}$ \\
\hline $\begin{array}{l}\text { Number of measurements } \\
\text { (N) }\end{array}$ & 8 \\
\hline Cutting length (Cut-Off) & $0.8 \mathrm{~mm}$ \\
\hline Filter & GAUSS \\
\hline
\end{tabular}

Table 1 Characteristics of roughness measurements

First, the calibration of the rugosimeter was verified. Where the average roughness value obtained $\left(R_{a}\right)$ was the same to the calibration block (Figure 6).
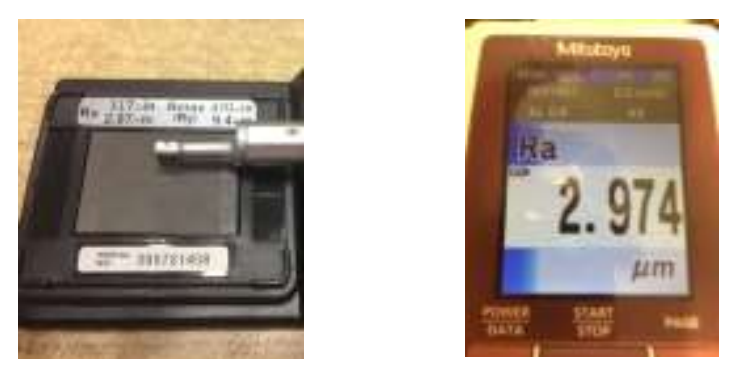

Figure 6 Verification of the calibration of the rugosimeter

Subsequently, the $\sigma$ measurements of the surface roughness of the axes were made (Figure 7).

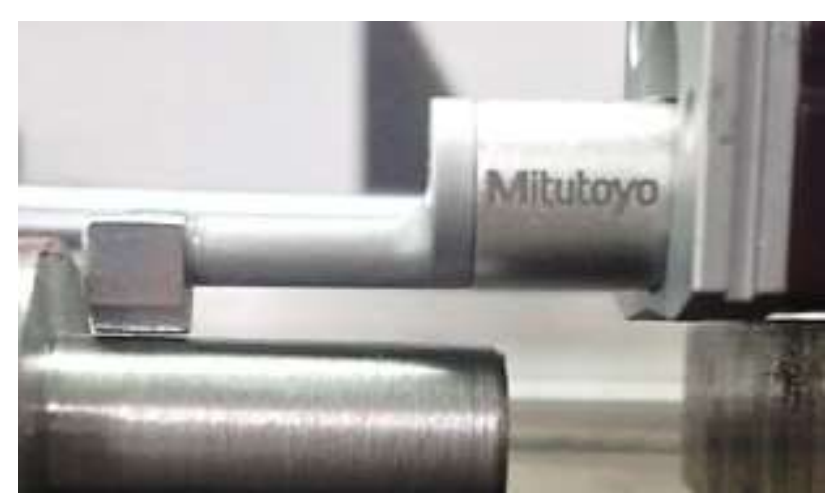

Figure 7 Measurement of $\sigma$ of the axes

The measurement with the roughness meter gives us the plot roughness profile of the axis. An example of the roughness profile for each surface finish (fine, medium and rough) is shown in Figure 8.

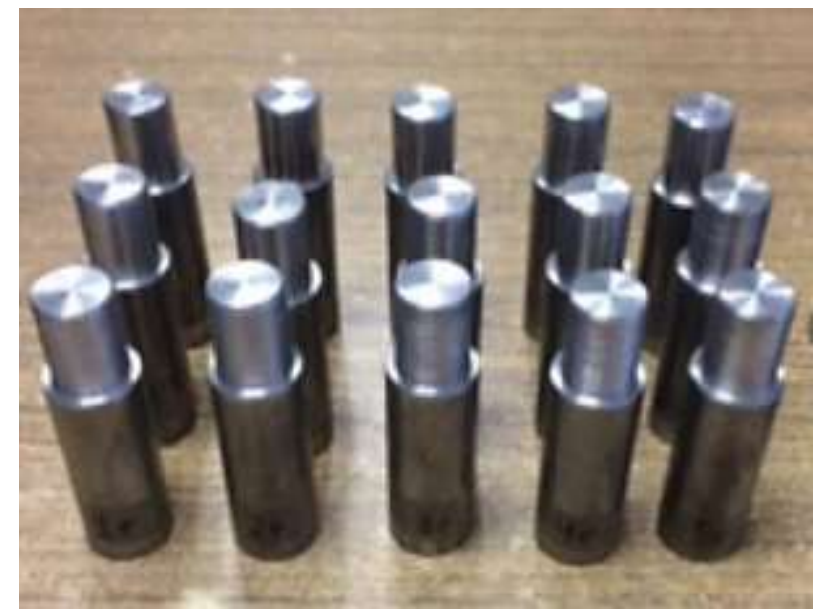

Figure 8 Machined shafts with different surface finishes (fine, medium and rough)
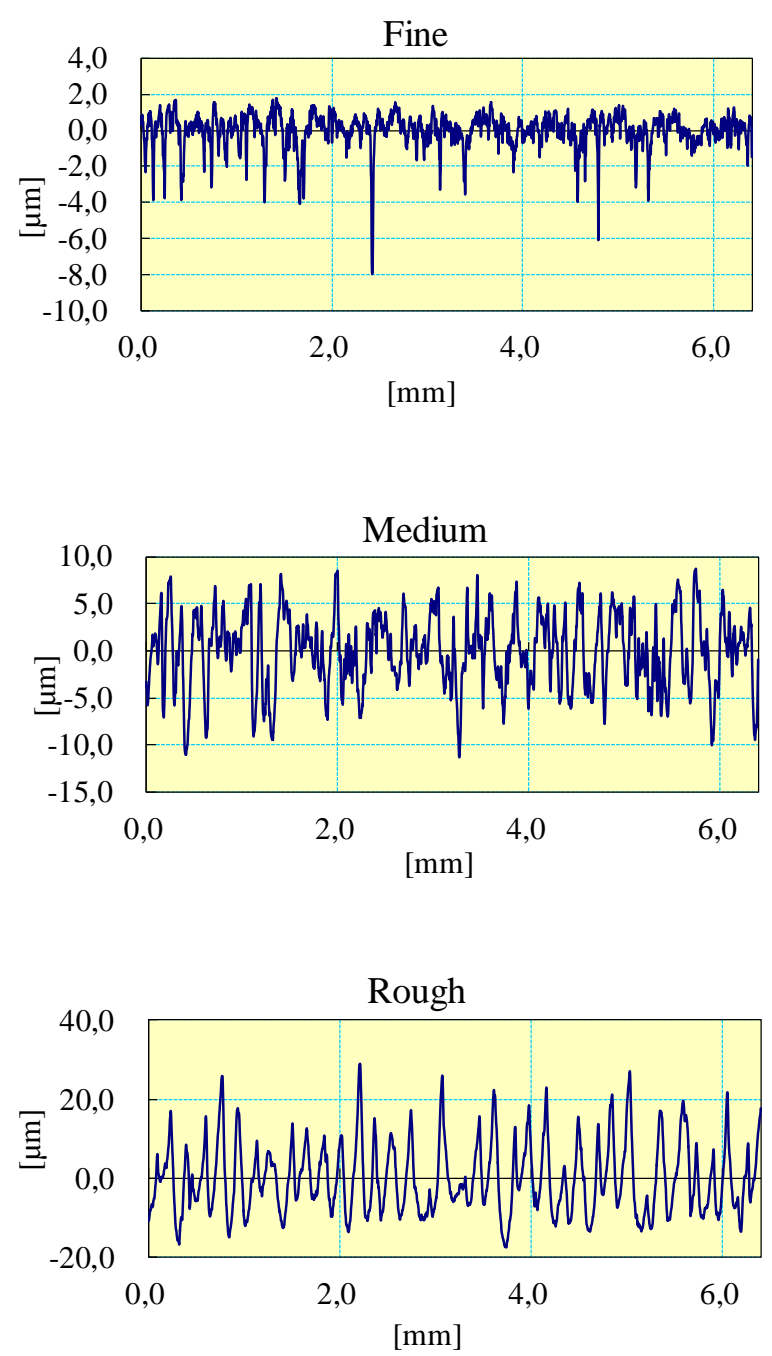

Figure 9 Example of roughness profile for each surface finish (fine, medium and rough)

The $\sigma$ values of the surface roughness measurements are also obtained. Table 2 shows the values of $\sigma$ obtained for the 15 axes and an average value of $\sigma$ is obtained for each surface finish. 


\begin{tabular}{|c|c|c|c|}
\hline \multicolumn{4}{|c|}{$\begin{array}{l}\text { Standard deviation }(\sigma) \text { of surface roughness in } \\
\text { microns }(\mu m)\end{array}$} \\
\hline Shaft & Fine & Medium & Rough \\
\hline 1 & 0.658 & 3.364 & 8.871 \\
\hline 2 & 0.684 & 3.093 & 8.165 \\
\hline 3 & 0.724 & 3.893 & 9.975 \\
\hline 4 & 0.946 & 3.769 & 9.058 \\
\hline 5 & 0.911 & 3.074 & 8.237 \\
\hline Average & 0.7846 & 3.4386 & 8.8612 \\
\hline
\end{tabular}

Table $2 \sigma$ values obtained for the 15 shafts

\section{Normal contact stiffness}

From Equation (11) of Buczkowski \& Kleiber (2016). Normal contact stiffness values were obtained $\left(k_{n}\right)$ according to the $\sigma$ of the roughness of the surface finish (fine, medium and rough) of the shaft and the minimum and maximum adjustment interference $\varnothing 20 \mathrm{H} 7 / \mathrm{s} 6$ (Table 3).

\begin{tabular}{|l|c|l|l|}
\hline $\begin{array}{c}\text { Surface } \\
\text { finish }\end{array}$ & \multicolumn{1}{c|}{} & Minimum $\boldsymbol{k}_{\boldsymbol{n}}$ & Maximum $\boldsymbol{k}_{\boldsymbol{n}}$ \\
\hline Fine & 0.7846 & 121930.4954 & 418047.4128 \\
\hline Medium & 3.4386 & 27821.40018 & 95387.65779 \\
\hline Rough & 8.8612 & 10796.12994 & 37015.30268 \\
\hline
\end{tabular}

Table 3 values of $k_{n}$ according to the $\sigma$ of the roughness of the surface finish (fine, medium and rough) of the shaft

\section{Model by finite element}

\section{Setting Data}

The shaft / hub joint analyzed has an interference setting of $\varnothing 20 \mathrm{H} 7$ / s6. The values of the diameters and the interference are shown in Figure 10.

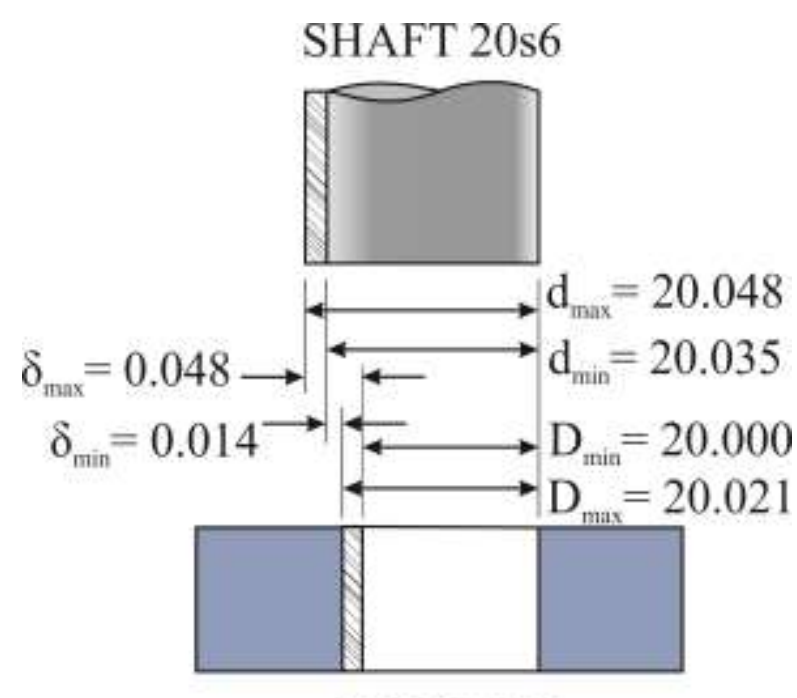

HUB $20 \mathrm{H} 7$

Figure 10 Adjustment values $\varnothing 20 \mathrm{H} 7$ / s6 for the finite element model in millimeters

\section{Material}

The material used in this study was AISI 1045 steel. The properties of this steel are shown in Table 4.

\begin{tabular}{|l|c|}
\hline Young's Module $(E)$ & $205 \times 10^{3} M P_{a}$ \\
\hline Poisson ratio $(v)$ & 0.29 \\
\hline Creep Effort $\left(\sigma_{y}\right)$ & $350 M P_{a}$ \\
\hline
\end{tabular}

Table 4 Properties of AISI 1045 steel

\section{Considerations}

The axis and the cube are drawn smooth. Only the surface roughness of the shaft is considered by means of a normal contact stiffness value $\left(k_{n}\right)$ in the interaction of the pieces. This in order to observe the effect of the finishing of the lathe (fine, medium and rough) on the shaft-hub joint.

The "interference fit" option is used to perform the assembly. The temperature used to perform the assembly is not considered.

The coefficient of friction depends on many parameters (i.e. interference, surfaces, work efforts, stress concentration, wear, assembly, temperature, among others). It is known that the coefficient of friction at contraction adjustment pressures is much lower than that indicated for low normal loads (Bhushan, 1999). Booker \& Truman (2004) have shown that the coefficient of friction is independent of the area. Therefore, the coefficient of friction is considered identical for each test. A conventional value of 0.15 is chosen between steel-steel.

The modeling is done with the finite element method using ABAQUS software.

\section{Numerical modeling}

The shaft and hub were created, they were assigned the same material (AISI 1045 steel). Two steps were declared for analysis; in step 1 the assembly is carried out by means of the option "interferece fit" of ABAQUS and in step 2 the axial extraction of the shaft is carried out to determine the load that supports the union.

SALGADO-CRUZ, Manuel, CORTÉS-GARCÍA, Claudia, SZWEDOWICZ-WASIK, Dariusz Slawomir and MARTÍNEZRAYÓN, Eladio. Strength of the shaft/hub joint using a finite element model. Journal of Scientific and Technical Applications. 2019. 
Figure 1 shows Step 1 "assembly" in an isometric view with a $180^{\circ}$ section.

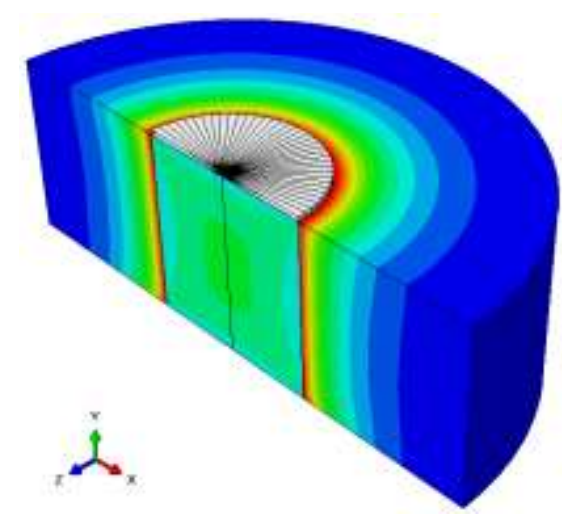

Figure 11 Step 1 "assembly" of adjustment Ø20 H7 / s6 for the finite element model

Two interactions formed; one between the axis and the hub, where the normal contact is a function of the contact stiffness of Equation (11), and a friction coefficient value of 0.15 is assigned to the tangential contact. The second interaction was made between the shaft and the rigid body to obtain the extraction force by means of the normal contact force by its acronym "CFN".

The boundary conditions were a recess in the lower part of the cube and a displacement of $20 \mathrm{~mm}$ in and on the reference point "RP" (see Figure 12).

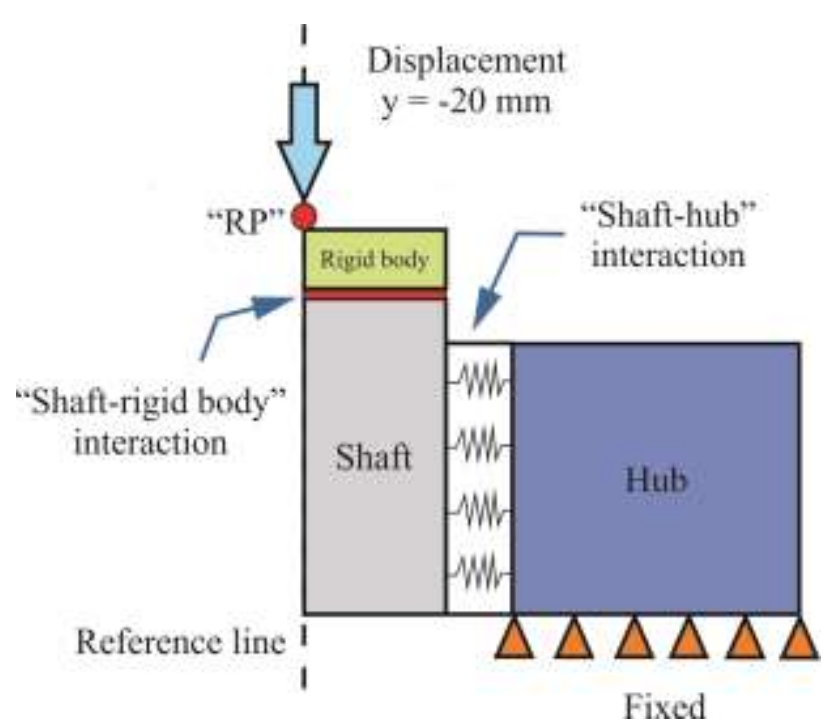

Figure 12 Boundary and loading conditions

Boundary and loading conditions were applied in Step 2 "extraction" (Figure 13), since in Step 1 "assembly" is performed without border conditions. The meshing of the pieces was $0.2 \mathrm{~mm}$.
The type of element that was used was the CAX4R ("A 4-node bilinear quadrilateral axisymmetric, reduced integration, hourglass control").

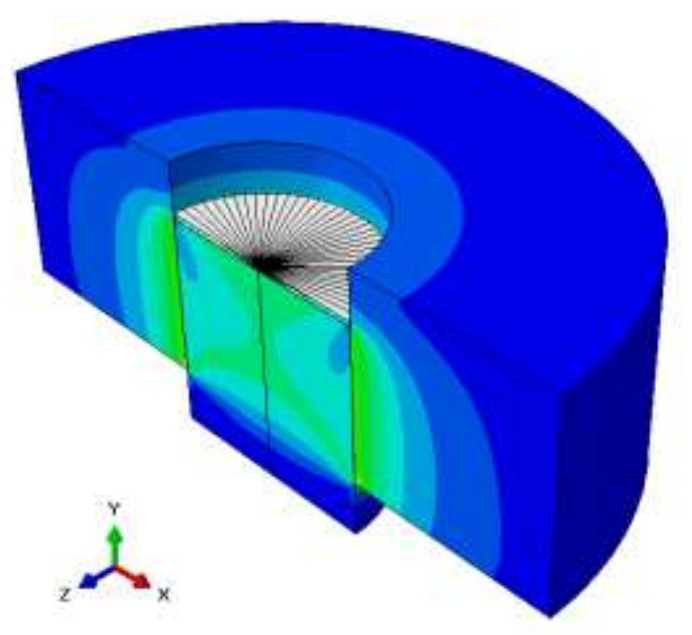

Figure 13 Step 2 "extraction" of the adjustment shaft Ø20H7 / s6

\section{Numerical - theoretical comparison}

First, a numerical-theoretical comparison was made to have a starting point for the study. Contact pressure and extraction force were compared in order to validate the model by finite element. The results are shown in Table 5.

\begin{tabular}{|c|c|c|c|}
\hline $\begin{array}{l}\text { Minimum } \\
\text { interference }\end{array}$ & Theoretical & Numerical & $\begin{array}{c}\% \\
\text { difference }\end{array}$ \\
\hline $\begin{array}{l}\text { Contact } \\
\text { pressure } \\
\text { (MPa) }\end{array}$ & 63.77 & $\begin{array}{l}62.81- \\
65.03\end{array}$ & $\begin{array}{l}-1.5- \\
1.97\end{array}$ \\
\hline $\begin{array}{l}\text { Extraction } \\
\text { force }(\mathrm{N})\end{array}$ & $12,021.82$ & $12,914.30$ & 7.7 \\
\hline $\begin{array}{l}\text { Maximum } \\
\text { interference }\end{array}$ & Theoretical & Numerical & $\begin{array}{c}\% \\
\text { difference }\end{array}$ \\
\hline $\begin{array}{l}\text { Contact } \\
\text { pressure } \\
(\mathrm{MPa})\end{array}$ & 218.66 & $\begin{array}{l}218.67- \\
225.07\end{array}$ & $\begin{array}{ll}0.004 \quad- \\
2.9\end{array}$ \\
\hline $\begin{array}{l}\text { Extraction } \\
\text { force }(\mathrm{N})\end{array}$ & $41,217.69$ & $44,278.40$ & 7.4 \\
\hline
\end{tabular}

Table 5 Numerical - theoretical comparison.

The variation of the contact pressure is attributed to the fact that in Equation (1) the same value is assigned for all the contact between the surfaces of the shaft and the hub. In contrast, in the finite element model the contact pressure increases in the center of the contact due to the coefficient of friction. These variations also contribute to an increase in the extraction force in the numerical model. 
Therefore, it does not mean that there are errors in the model by MEF, but that the contact pressure equation does not consider these variations. Graphs 1 and 2 show the comparison of the contact pressure for a minimum and maximum interference of the setting Ø20H7 / s6 respectively.

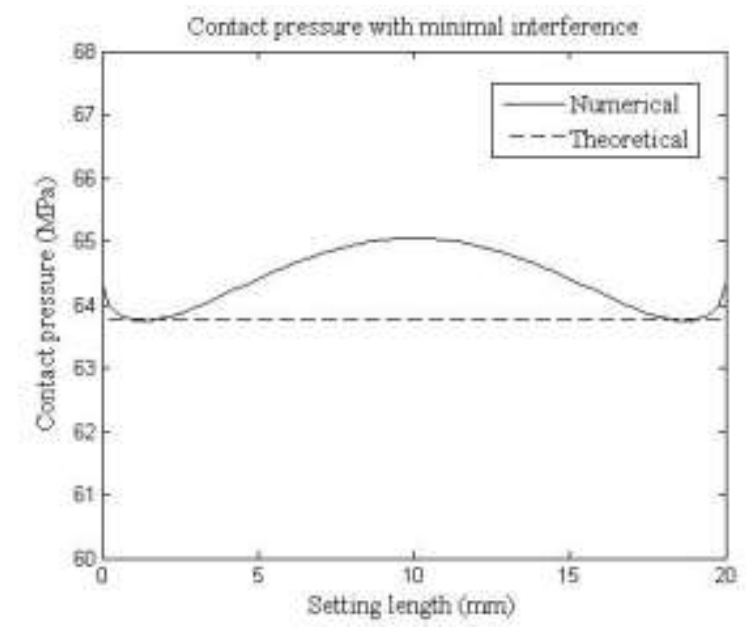

Graph 1 Contact pressure with minimal interference

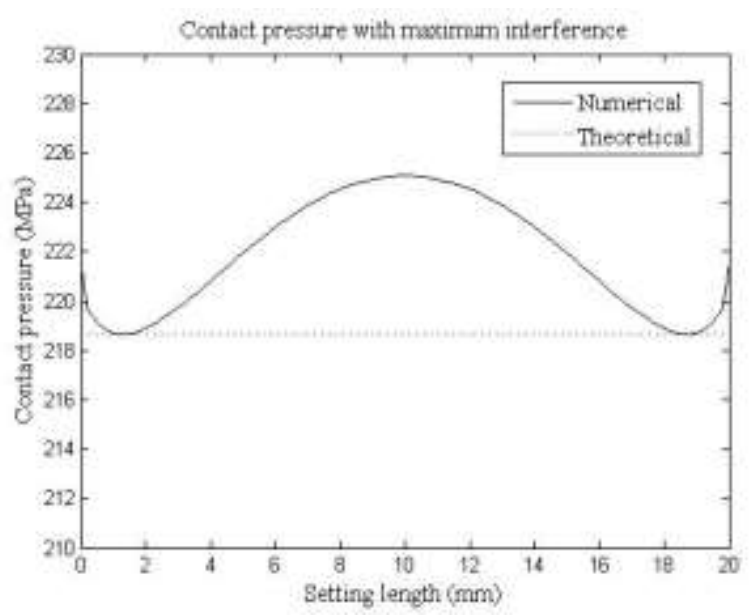

Graph 2 Contact pressure with maximum interference

\section{Results}

Table 6 shows the results obtained from the extraction force of the model by the finite element method of the shaft-hub joint with interference adjustment $\varnothing 20 \mathrm{H} 7$ / s6, where the standard deviation of the three finishes was analyzed (fine, medium and rough).

And it was compared with results of a smooth model (without roughness). In the end the percentage of difference with respect to the smooth model was determined.

\begin{tabular}{|l|l|l|l|}
\hline $\begin{array}{l}\text { Surface } \\
\text { finish }\end{array}$ & $\begin{array}{l}\boldsymbol{\sigma} \\
\text { (microns) }\end{array}$ & $\begin{array}{l}\text { Minimum } \\
\text { extraction } \\
\text { force (N) }\end{array}$ & $\begin{array}{l}\text { \% difference } \\
\text { from smooth }\end{array}$ \\
\hline--- & Liso & $12,914.30$ & ------ \\
\hline Fino & 0.7846 & $11,975.50$ & -7.26 \\
\hline Medio & 3.4386 & $9,556.59$ & -25.99 \\
\hline Rugoso & 8.8612 & $6,767.86$ & -47.59 \\
\hline $\begin{array}{l}\text { Surface } \\
\text { finish }\end{array}$ & $\begin{array}{l}\text { Dev. } \boldsymbol{\sigma} \\
\text { (microns) }\end{array}$ & $\begin{array}{l}\text { Maximum } \\
\text { extraction } \\
\text { force (N) }\end{array}$ & $\begin{array}{l}\text { \% difference } \\
\text { from smooth }\end{array}$ \\
\hline--- & Liso & $44,278.40$ & ------ \\
\hline Fino & 0.7846 & $43,270.10$ & -2.27 \\
\hline Medio & 3.4386 & $40,137.80$ & -9.35 \\
\hline Rugoso & 8.8612 & $34,982.00$ & -20.99 \\
\hline
\end{tabular}

Table 6 Results of the extraction force according to the standard deviation values of the roughness

The minimum and maximum extraction force of the shaft - hub joint along its $20 \mathrm{~mm}$ of adjustment length (Graphs 3 and 4) was also plotted. The Graphs show the comparison of the different finishes (fine, medium and rough) with respect to the smooth one (without roughness).

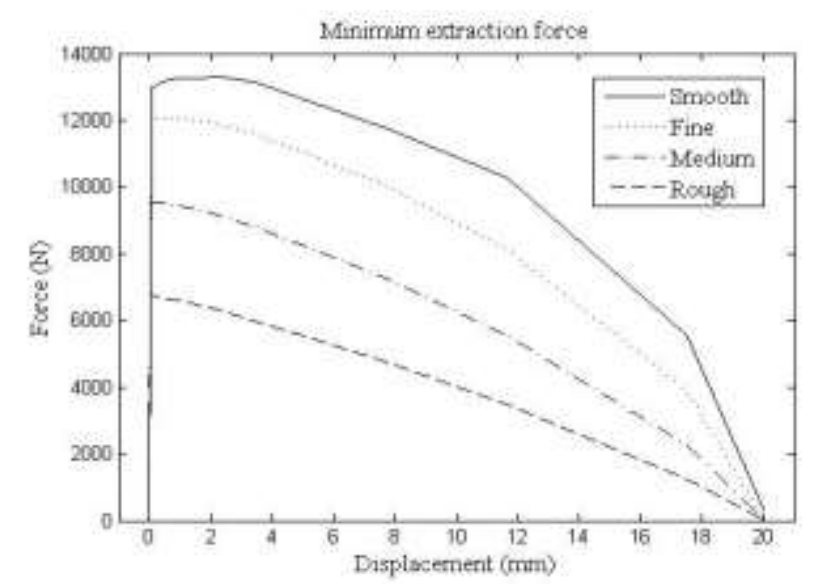

Graph 3 Minimum extraction force

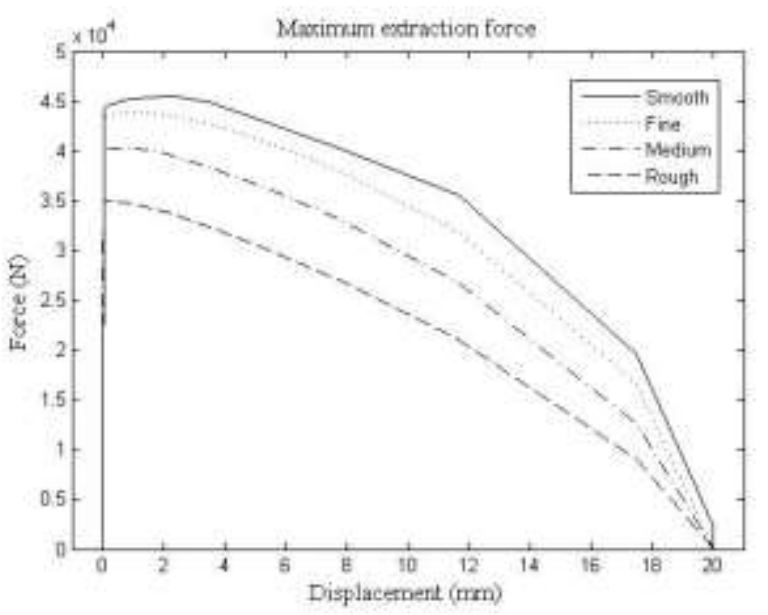

Graph 4 Maximum extraction force 
Finally, the variation of the extraction force ranges of the different surface finishes obtained from a conventional lathe was plotted. The extraction force range is a result of the tolerance of the $\varnothing 20 \mathrm{H} 7$ / s6 adjustment. Graph 5 shows the ranges of the different finishes (fine, medium and rough) compared to smooth (without roughness).

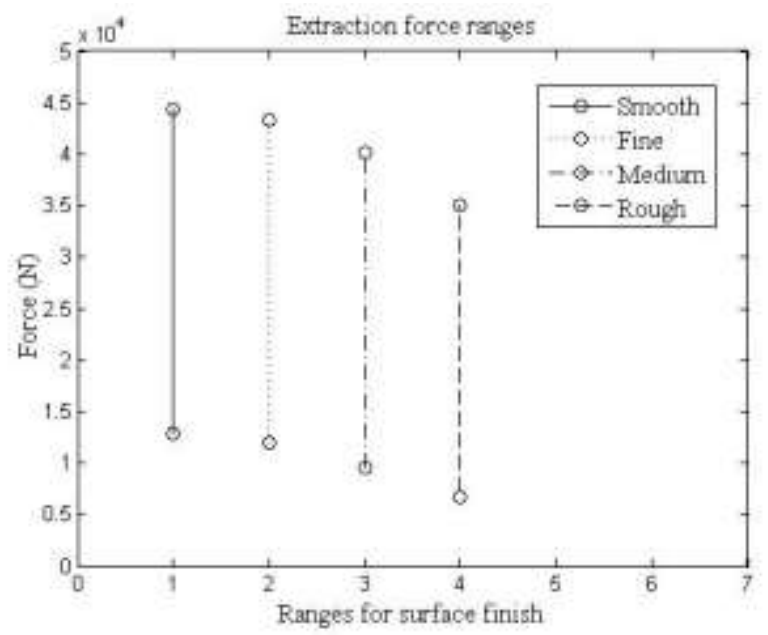

Graph 5 Extraction Force Ranges

\section{Conclusions}

The results obtained show that the larger surface roughness contributes to the reduction of the load capacity of this type of joints. For the three surface finishes (fine, medium and rough) the extraction force was reduced.

Due to the surface roughness, the $\varnothing 20 \mathrm{H} 7$ / s6 adjustment of the joint reduces its load capacity range up to 47.59 and $27.99 \%$ for a rough finish for minimum and maximum interference respectively. For this reason, surface roughness must be taken into account in order to have optimum performance of the shaft / hub joints with interference.

The modeling of the axis - hub joints by means of normal contact stiffness to represent the complex geometry of the surface roughness of the pieces, generates a light and practical modeling since many times the roughness modeling complicates this type of analysis by the large amount of mesh to be used and irregular surface contact, which is reflected in an increase in computational cost. It should also be noted that it would be important to analyze the local behavior of the roughnesses in the contact interface of the axis - hub connection.

\section{Recommendations}

For engineering applications, it is recommended to consider the surface roughness of the machining process in the shaft / hub joints. Since the strength of the joint decreases as the roughness increases. Also, it should be taken into account that a better finish implies an increase in cost. Therefore, use this finite element model that uses a normal contact stiffness $\mathrm{k} \_n$ equivalent to the surface roughness size. It would help to make a better decision.

\section{Acknowledgements}

We thank the National Council of Science and Technology (CONACYT), for the financial support granted for the development of this project. Likewise, to the National Center for Research and Technological Development (CENIDET) for all the support provided and the academic training provided through its researchers.

\section{References}

Bhushan. (1999). Principles and applications of tribology. (Wiley, Ed.).

Booker, \& Truman. (2004). A comparison of shrink-fit holding torque using probabilistic, micro-mechanical and experimental approaches. Proc Inst Mech Eng, part B, 17587.

Booker, \& Truman. (2011). Measuring the coefficient of friction for use in shrink-fit calculations. TECHNIQUES, (April), 7-13. http://doi.org/10.1111/j.1747-1567.2009.00593.x

Boutoutaou, Bouaziz, \& Fontaine. (2011). Modeling of interference fits taking form defects of the surfaces in contact into account. Materials and Design, 32(7), 3692-3701. http://doi.org/10.1016/j.matdes.2011.03.059

Boutoutaou, Bouaziz, \& Fontaine. (2013). Modelling of interference fits with taking into account surfaces roughness with homogenization technique. International Journal of Mechanical Sciences, 69, 21-31. http://doi.org/10.1016/j.ijmecsci.2013.01.012 
Buczkowski, \& Kleiber. (2016). A study of the surface roughness in elasto-plastic shrink fi tted joint. Tribiology International, 98, 125-132. http://doi.org/10.1016/j.triboint.2016.02.021

Budynas, \& Nisbett. (2008). Diseño en ingeniería mecánica de Shigley. México, D.F.: The McGraw-Hill.

Ramachandran, \& Radhakrishnan. (1974). Influence of surface finish on interference fits. International Journal of Production Research, 12(6), 705-719. http://doi.org/10.1080/00207547408919587

Yang, Coquille, Fontaine, \& Lambertin. (2001). Influence of roughness on characteristics of tight interface fit of a shaft and a hub. International Journal of Solids and Structures, 38(42-43),

7691-7701. http://doi.org/10.1016/S0020-7683(01)00035-X

Yang, Coquille, Fontaine, \& Lambertin. (2002). Contact pressure between two rough surfaces of a cylindrical fit. Journal of Materials Processing Technology, 123, 490-497. 